\title{
La Pandemia atraviesa a Todo
}

La situación de Pandemia Global nos obliga a empezar la síntesis y presentación de este Anuario del Conflicto Social 2019 por el final, así como nos ha motivado para crear una nueva sección que aparece en el orden visual de esta publicación al final de la misma.

La pandemia de Covid-19 permea todos los aspectos de nuestra vida cotidiana convirtiendo en más acuciantes las desigualdades de género y clase; modificando los significados de la salud y la enfermedad; alterando nuestros ritmos y rutinas de trabajo, la vida cotidiana, el carácter, tipo y orden de nuestras preocupaciones, el grado de presión de los intereses individuales y colectivos, y la urgencia, para muchas personas, de resolver sus necesidades más básicas relacionadas con asegurar la salud o con encontrar los medios de subsistencia... De todo ello nos hubiera gustado poder dar cuenta a través de esta publicación; esto no ha sido del todo posible, pero esperamos contribuir de alguna manera con este objetivo en los próximos números. Por el momento solo nos vemos capaces de ofrecer alguna idea o matiz general de la situación, y lo hacemos de la mano de alguna de las obras importantes de la Sociología contemporánea.

Randall Collins, en su obra titulada Cadenas de rituales de interacción ${ }^{1}$, nos propone una teoría y un esquema conceptual con los que explica la importancia que tienen las emociones implicadas en la interacción social,

1 De esta obra disponemos de una edición en castellano del año 2009 en la editorial Anthropos. 
núcleo básico de la articulación de cualquier estructura y dinámica sociales, por ejemplo, para la articulación y el funcionamiento de instituciones y organizaciones, para las dinámicas de acción colectiva y la creación de redes de confianza y cooperación, para las rupturas y fracturas que derivan en condiciones de desigualdad o en la activación de conflictos, etc. Para este sociólogo, el entramado de una sociedad completa puede ser radiografiado y descompuesto en ese conjunto de unidades pequeñas que son los rituales específicos, producidos y reproducidos (también modificados) por las interacciones sociales.

Hasta ahora así habíamos entendido su obra y así nos habíamos acercado a su propuesta cuando hemos recurrido a ella con intenciones analíticas y explicativas. Sin embargo, el momento presente de Pandemia Global nos ha puesto delante un contexto inmediato de tal envergadura y particularidad que ahora vamos a poder entender su sociología, no ya sólo teóricamente sino vivencialmente. Vamos a entender qué significa y por qué Collins ha subrayado tanto el valor que tiene la energía emocional implicada en la interacción social, o vamos a entender con precisión qué significan y qué valor tienen los rituales sociales por sí mismos. Porque en estas circunstancias reconocemos su significado de manera plena, precisamente cuando los espacios sociales que hacen posible la interacción están quedando en grado importante suspendidos: tenemos restringida la posibilidad de réplica espontánea de muchos de los rituales sociales a través de los que nos relacionábamos y con ello hemos perdido, fundamentalmente también, parte de la energía emocional que circula por y conforma el vínculo social.

De la COVID-19 se van a derivar muchas consecuencias dramáticamente negativas, con toda seguridad, ya lo estamos viendo y viviendo. Pero la pandemia también nos está enseñando, en positivo, el valor intrínseco de cualquier vínculo social, también nos está recordando el sentido olvidado de lo comunitario, que, habiéndolo dado por descontado antes de esta situación, ha sido despreciado y devaluado por los impulsos individualistas con los que 
se han formateado el conjunto de las actuales sociedades que, en esencia, son devoradoras de recursos y aniquiladoras de cualquier forma posible de existencia si ésta se desvía del patrón principal de la competición individualista.

La COVID-19 nos está obligando aceleradamente e improvisadamente a la invención de nuevas cadenas de interacción, a la búsqueda de nuevos ritos y de respuestas sociales que suplan y completen los espacios sociales que han sido interrumpidos: hemos suspendido la posibilidad de trabajo para muchos y hemos abocado a otros al teletrabajo, y vemos la urgencia de tener que asegurar la subsistencia para los que no pueden trabajar, o de modificar, para los que sí pueden, las pautas laborales que conocían; hemos suspendido la posibilidad del encuentro fácil entre amigos y familia, y buscamos otras maneras de mantener las relaciones de afecto y cuidado; hemos suspendido, parcial o totalmente, las relaciones sociales implicadas en la formación y la educación tal y como las conocíamos, y buscamos otra manera de seguir estudiando, aprendiendo y enseñando; hemos cerrado, parcial o totalmente por momentos, los centros de consumo compulsivo, incluyendo también en estos a los lugares de huida, ocio y distracción que etiquetamos, con cierto sentido eufemístico, como "el mundo de la cultura", etc.

Pero todo lo que nombramos es tan solo una parte de lo que está sucediendo dentro de los contornos del mundo más rico. Ese precisamente es al que queremos dirigir una especie de reclamo o denuncia, porque es el que probablemente más había olvidado el valor de la comunidad, del vínculo, de la interacción repetida, en definitiva, se había olvidado el verdadero valor de lo social.

La COVID nos enseña también, si tenemos el valor de aprenderlo, que hemos tolerado y sido cómplices individuales (pero no en igualdad de responsabilidades, hay que recordarlo) de sociedades que han alimentado de armamento a ejércitos, que han promocionado guerras, y lo siguen haciendo. También que hemos disociado cognitivamente naturaleza y humanidad, de 
una manera tan irracional y tan completa que en nuestra práctica cotidiana se olvida - con una facilidad y una ligereza que ahora nos abruman- tanto nuestra dependencia hacia la naturaleza como el hecho de que somos parte de ella. En el extremo de esta disociación, hemos llegado a generar discursos (y muy probablemente a pensar en consonancia con ellos) en los que se afirma que defendernos de la COVID consiste en atacarla, como si de una más de nuestras guerras humanas se tratara. Nos está costando asumir todo lo que hemos hecho en contra de la naturaleza, de la que no somos más que una parte minúscula. Y nos está costando poner esfuerzo en reconocer que nuestras capacidades como especie y las riquezas que hemos sido capaces de generar las hemos ido colocando en los peores lugares posibles, porque no están puestos a favor ni de un mejor sistema de salud, ni de investigación, ni de educación, ni de asegurar la subsistencia para los que no pueden hacerlo por sí mismos, ni están, por tanto, a favor de articular ningún vínculo real, aquel que favorece vivir en comunidad tanto con los miembros de nuestra especie como con la propia naturaleza.

Desde este Anuario del Conflicto Social 2019 (que se está editando entre los meses de Octubre de 2020 y Enero de 2021), no podíamos dejar de, al menos, nombrar el marco con el que pensamos este año atravesado por la pandemia COVID-19. Como tampoco podíamos dejar de publicar los materiales y los análisis que nos han llegado sobre esta situación (un tipo de análisis del que, sinceramente, nos hubiera gustado poder disponer de más). Es por ello que tuvimos que "improvisar" esta nueva Sección Covid, (a la que de manera concreta nos vamos a referir a continuación) y con ella tuvimos también que romper la norma (propia de un anuario) de publicar sólo estudios relacionados con el año que antecede o balances de conflictos en recorrido temporal hacia atrás y, para este número, previos a 2020.

En esta nueva sección (que deseamos que sea lo más breve posible en años de existencia) hemos incluido cuatro elementos de los cuales tres pertenecen a Guillem García, que los ha elaborado con la intención de captar una parte 
de la información que los medios de comunicación iban suministrando en medio del estallido inicial de la pandemia, las primeras semanas de desconcierto y de confinamiento en España. Estos tres primeros elementos publicados en esta sección componen una unidad, no sólo porque pertenecen al mismo autor, sino porque cada uno de ellos deriva (y en parte obliga) a la consulta del otro. Su autor ha puesto a nuestra disposición, además de su propia aportación en forma de análisis, un material rigurosamente seleccionado y ordenado sobre lo que los periódicos Ara y La Vanguardia ofrecieron en sus publicaciones diarias. Creemos en el valor intrínseco de este esfuerzo y por eso lo hemos publicado, además de que son materiales que pueden ser aprovechados para ser analizados, con otras intenciones o enfoques, en trabajos futuros de investigación. Estos tres primeros elementos de la sección están identificados como la Cronología informativa sobre la pandemia COVID en España (antecedentes) y la recogida formal y sistemática del material informativo que dan contenido a sus Anexos.

El cuarto elemento de esta nueva sección lo aporta Joana Soto con un artículo en catalán en el que se evalúa el comportamiento inicial de los poderes políticos y su conexión con los expertos científicos de ámbito catalán y español durante los primeros momentos de la pandemia y del confinamiento obligado en este mismo ámbito territorial. Es la opinión particular y la reflexión de su autora la que guía la respuesta a la pregunta que se formula en el artículo (y que da título al mismo) sobre si ¿Tiene ideología el confinamiento? Nosotros respetamos lo allí expuesto - no puede ser de otra manera-, pero esencialmente creemos que su publicación puede servir como testimonio representativo del momento inicial que estábamos viviendo (aunque muy circunscrito al contexto catalán y español). Además de eso, pensamos que, entre esas primeras semanas, impresiones y actuaciones, el texto puede dejar entrever una especie de rastro de lo que puede ser alguna de las claves -entre las muchas que van a componerla- de la compleja disputa social derivada de la pandemia. 
A partir de aquí, la presentación de este nuevo número del Anuario transcurre como siempre: refiriendo las tres secciones usuales y los artículos que las componen.

En la Sección I, identificamos conflictos cuyo foco de activación temporal transcurrió centralmente en el año 2019. Por suerte hemos podido contar con el trabajo de Teresa Aritzia y Ángeles Bustamante para tratar el estallido del conflicto social chileno que, a través de los distintos medios, llegó a todo el mundo y que nos preocupó a muchos, tanto como en algún sentido nos abrió una ventana para la esperanza. Lo que estas autoras nos ofrecen, tal y como han titulado su análisis, es una Radiografía del conflicto chileno: una democracia representativa en crisis.

Sobre el mismo país y el mismo foco, también contamos, en la misma sección, con el trabajo de Natalie Rojas sobre el proceso de feministización que atraviesan los movimientos sociales en Chile. Este trabajo, aunque se inspira en la esperanza que alienta al movimiento de alcanzar a dar cuerpo a una constitución feminista, alerta de que la simple paridad en la conformación del órgano constituyente no asegura que el feminismo esté dentro de la nueva constitución. Todo su análisis aboga, como el propio movimiento de mujeres chilenas, por alcanzar a "hacer de la nueva constitución un instrumento jurídico feminista". Y el título de este análisis es Movimientos de mujeres en Chile y el camino hacia una constitución feminista.

En esta misma sección aparece el artículo de Ricardo Cuevas 'Perdimos mucho tiempo peleando entre nosotros': aproximaciones teóricas a la participación de barras de fútbol en la revuelta sociopolítica chilena de 2019-2020, que también hace referencia a la revuelta chilena. En este caso el autor se centra en el análisis del papel que han tenido las prácticas de las barras de fútbol y el protagonismo que han tenido en determinados momentos de la revuelta. El autor es capaz de hacer una muy buena conexión entre algunos de los rasgos que han predominado en la movilización chilena y las prácticas de este colectivo, y ha sido capaz de elaborar una adecuada descripción sobre cómo el colectivo de las "barras de 
fútbol", considerado transgresor, ha funcionado como agente tensionador y ha reconfigurado la realidad sociopolítica y cultural existente.

Cierra la sección The Daphne Protests at the End of 2019. A Chronology, de Michael Briguglio, sobre el ciclo de movilizaciones en Malta que culminó con la dimisión del primer ministro del país a inicios de 2020. Sin mencionarlo explícitamente, la cronología ejemplifica bien algunos de los mecanismos determinantes de la progresión de la contienda política detectados por Doug McAdam, Sidney Tarrow y Charles Tilly en Dinámica de la contienda política, como la certificación/descertificación exterior de los actores nacionales, la correduría y formación de coaliciones (nacionales e internacionales) o la atribución de oportunidad política. Más interesante aún es la descripción del funcionamiento de dichos mecanismos en un Estado pequeño en el que existen "fuertes conexiones entre líderes [políticos] y sus votantes, una reducida esfera privada, un escaso papel [en la política] de la ideología y del debate sobre políticas y programas, una fuerte polarización, una gran presencia del clientelismo [...]”, un país, además, que, según el autor, parece en vías de convertirse en una "democracia de partido único", término de Godfrey Baldacchino (tal y como reza en el artículo) que engloba los sistemas políticos de países como Japón, Singapur o Suecia, donde "un partido político convencional, típicamente centrista, se erige en el preservador de una 'coalición voluntaria de intereses". Consideramos que este trabajo puede ser un buen punto de partida para análisis futuros más desarrollados teóricamente sobre este ámbito y tema y, desde aquí, animamos a hacerlo.

En la Sección II, recogemos estudios que refieren a la consideración de estructuras y procesos para el conflicto social y este año, con el análisis de Esther G. Pineda ponemos la mirada, tal y como lo expresa la autora, en "las condiciones para la organización y movilización de las familias de las víctimas de femicidio, cuyo accionar ha permitido su visibilización, ha llamado la atención de los medios de comunicación, ha permitido la contabilización de los crímenes, ha convocado a los organismos internacionales, ha 
comprometido al movimiento feminista, ha logrado la tipificación del delito, pero principalmente continúa demandando justicia”. El título de su artículo, Organización, movilización y acción familiar y feminista ante el femicidio en América Latina, es una buena expresión de lo que nos ofrece: es, por un lado, una contribución desde el mundo académico para la toma de conciencia general de la población y para la activación de las demandas en contra del femicidio y, por otro, es una fuente de información de los datos disponibles y espeluznantes sobre el feminicidio en América Latina.

En la Sección III, de Balances y consecuencias para el cambio, encontramos el artículo de Anna Moreno y Clara Camps La respuesta del movimiento feminista a la violencia sexual en el espacio público. La agresión sexual múltiple en las fiestas de San Fermin de 2016 como punto de inflexión, que reflexiona sobre la respuesta, en 2018, del movimiento feminista ante la primera sentencia judicial del caso de "La Manada". El artículo considera que la respuesta feminista en las calles permitió abrir un "nuevo marco de referencia" sobre la violencia sexual y el consentimiento, que acabaría penetrando en los medios de comunicación, en la ciudadanía e incluso en el ámbito político y legislativo. Además, las autoras explican cómo el movimiento feminista, durante el año 2019, fue capaz de seguir ampliando y complejizando el discurso sobre la violencia sexual poniendo el acento en las relaciones entre la violencia sexual y las instituciones del Estado. Con su análisis, las autoras han sabido captar el complejo proceso en el que se combinan discursos de la calle, discursos de los medios y discursos jurídicos, y han sabido señalar cuáles han sido sus efectos, que en el artículo se concretan en ciertos reajustes y extensión significativa del propio discurso que los colectivos feministas ya llevan muchos años trabajando.

Esta presentación la cerramos con un mensaje de agradecimiento para todos los autores que han depositado su confianza en nosotros. Y con un mensaje muy especial de recuerdo para todos los que en este contexto más han sufrido, o están sufriendo, o han perdido la vida por la COVID-19. 
Nosotros, el colectivo de personas que colaboramos en el Observatorio del Conflicto Social ${ }^{2}$, lamentamos la pérdida de Salvador Aguilar que fue profesor de Sociología durante dos largas décadas de trabajo intenso en la Universidad de Barcelona, y que no solo formó parte de nuestro colectivo hasta 2014 sino que alentó y contribuyó en el impulso inicial del proyecto editorial de nuestra revista.

Desde estas páginas deseamos que, desde cualquier lugar donde estemos, todos busquemos la manera de encontrar los vínculos necesarios para cuidarnos mejor, iy más!

María Trinidad Bretones, Jordi Bonet, Clara Camps y Joan Quesada Universidad de Barcelona

Barcelona, Enero de 2021

\footnotetext{
${ }^{2}$ Este colectivo lo integran, además de los firmantes de este texto, en España, Jaime Pastor y Joan Linio; en Chile, Sandra Vera Gajardo y Nincolás Rojas Pedemonte, y en Colombia, Ximena Cuadra y Carlos Andrés Charry.
} 